\title{
Do Poder Judiciário
}

\section{Alfredo Balthazar da Silveira}

\section{A} SUPREMACIA, contra a qual aqui se estão levantando agora os interêsses politicos, a supremacia da justiça na solução das questões de constitucionalidade, é a grande característica do regime e a sua garantia suprema. Ainda os melhores publicistas europeus, dentre os quais, falando nos mais modernos, bastaria citar o de BouTMY, essa posição constitucional da Justiça dos Estados Unidos se considera como «uma das invenções mais originais, inesperadas e admiráveis, que na história do direito público se encontram. ToCQUEVILE, com sua imensa autoridade, a encarecia como «uma das mais poderosas barreiras, que nunca se elevaram contra a tirania das assembléias políticas». (Rur Barbosa, discurso no Instituto dos Advogados Brasileiros - Maio de 1911). «Temos, nesse caráter, uma função constitucional altíssima e melindrosissima... esta Côrte Suprema maneja a balança dos podêres políticas. Desempenha assim a atribuição engendrada pelo insigne publicista francês BENJAMin Constant, a qual foi adotada pela nossa carta constitucional de 25 de março de 1824 , que ao respectivo órgão deu a denominação do Poder Moderador. A competência precípua dêsse poder, em nosso regime presidencial de constituição rígida, pertence ao judiciário federal, como na sua Organisation Judiciaire Aux Etats-Unis o mostra Nerinx. Incumbe-lhe, nesse caráter, a função específica de contrastear os atos dos outros órgãos da soberania nacional. Acareia-os com a Constituição e as leis. E deixa de aplicar às espécies ocorrentes os que são manifestamente inconstitucionais ou ilegais. Protege, assim, os direitos individuais, por êles lesados. Desgosta, como é natural, os representantes dêsses outros podêres. Ao revés, porém, cumpre ditos atos, desde que não exorbitem da lei primária e das ordinárias» (Edmundo Lins - saudação ao Dr. Gabriel Terraem em 20/8/1934). «A concepção do judiciário como guarda da Constituição - adverte H. C. BLACK - prevaleceu no sistema inglês e foi imaginado como um baluarte contra os abusos do rei e do parlamento em muitas ocasiões dignas de reparos». «Se um ato legislativo se opõe a um princípio constitucional, o primeiro deve ser abandonado e rejeitado com aversão. Sustento ser uma posição igualmente clara e correta, que em tal caso será dever da côrte aderir à Constituição e declarar o ato nulo e írrito». (Pronunciamento do Juiz PATtersonin, Oswaldo Aranha, Bandeira de Mello - A Teoria das Constituições Rigidas - p. 92 - 1934).

Apoiando-me em autoridades juridicas de tamanha valia, desenvolverei modestas considerações com o intuito de salientar a indisfarçável relevância, atribuída, nos regimes democráticos, ao poder judiciário, que, isento das paixões geradas por quaisquer motivos, se não deve investir de outra preo- 
cupação senão a de ver inteiramente observados os principios do Direito, conceituado pelo velho AHRENS - «le développment harmonieux de la personnalité».

Ora, se em épocas distanciadas daquela em que vivemos e na qual as nossas atividades se desdobram, em funções de julgar se confundiam com as de administrar, de modo que se não conheciam discriminações de atribuições públicas, não obstante a sábia advertência de ARISTóteles - «maestro di collot che sanno» - «deliberar, executar e julgar eram as principais funções sociais» - é claro que, na hodiernidade, ninguém se abalançará a propugnar o estabelecimento de um órgão político, encarregado de absorver os outros, o que importaria na implantação do totalitarismo.

O Estado, segundo a lição de José Higino Duarte Pereira, não pode ser concebido sem órgãos, porque, sendo pessoa coletiva não existe enquanto não está constituído, a sua constituição consiste na criação de um sistema de órgãos»; logo, quando uma sociedade se organiza politicamente, isto é, quando alcança a sua soberania, cuida de dividir, por entre departamentos adequados as suas necessidades, as funções, que são criadas para que seja atingido o bem comum.

E quer os gregos, quer os romanos, apesar de versados aquêles nos estudos filosóficos, e cultores êstes do Direito, nunca praticaram a divisão dos podêres, talvez porque não tivessem enxergado a verdadeira concepção dos direitos pessoais, talvez porque preferissem a supremacia do Estado, diante da qual desapareceriam os lídimos interêsses individuais.

Giovanni UGo vislumbrou um ensaio da separação dos podêres no período medieval, considerado por Augusto CoMTE a obra-prima da inteligência humana em alguns reinos e algumas comunas, em que a soberania se partilhava em certos órgãos: os cônsules (podestá), os conselhos maiores ou menores e os congressos de todo o povo.

JoHN LOCKE - filósofo inglês - movido pelo desejo de agradar a GuILHERME II - outrora príncipe de Orange - admitia quatro podêres políticos - o executivo - o legislativo - o federativo - ao qual competia declarar a guerra, aprovar a cessação de hostilidade - e o discricionário - exercido pelo monarca, que poderia adotar qualquer medida considerada útil ao Estado, segundo o seu próprio entendimento.

Mas, no correr do ano de 1748, a célebre obra - «Éprit des Lois» da autoria de Montesquier - antigo Presidente do Parlamento de Bordeaux e já conceituado pelo sucesso das «Lettres Persanes» - granjeou inúmeros leitores, alcançou, em dezoito meses, vinte e duas edições, o que indicava um grande triunfo político. Cabe, por conseguinte, a MontesquiER a glória inacessivel de haver focalizado, tornando acessivel aos homens, o problema da distinção dos podêres públicos; e, compreendido em suas altas finalidades cívicas, perceberam êles que da sua adoção adviria a maior segurança para as suas liberdades.

Suas idéias mereceram o apoio de Blachstone, de Bagelot, de Paley, e podem ser assim enumeradas: «Há em cada Estado, acentuava êle, três espécies de podêres: O Poder Legislativo, o Poder Executivo, que se incumbe das coisas e fatos que dependem do Direito das Gentes, e o Poder Executivo, que se encarrega das coisas e fatos que dependem do direito civil. O principe 
ou magistrado é quem exerce o primeiro poder (legislativo), cabendo-lhe, por conseguinte, fazer as leis, corrigir ou revogar as existentes. Fazer a paz ou a guerra, designar os embaixadores e receber os plenipotenciários estrangeiros, garantir a ordem pública e evitar as invasões estrangeiras, eis as atribuições do segundo poder. Punir os crimes e decidir das demandas entre os particulares, eis o que compete ao terceiro poder». Protegidos ficarão os direitos. Na Constituição do Estado de Virgínia (1776) e, também na Carolina do Norte (1776); de Maryland (1777); de Georgia (1777); de Massachusetts (1780); deparamos o princípio da completa separação dos podêres, a fim de que nenhum dêles pudesse praticar atos da exclusiva competência dos outros. Na Declaração dos direitos do homem e do cidadão está consignado no artigo 16: - Toute société, dans laquelle la garantie des droits n'est pas assurée ni la separation des pouvoirs determinée, n'a pas de constitution»; e, destarte, as constituições promulgadas, ou outorgadas, após a publicação do livro de Montesquier, admitiram o seu pensamento. E o Poder Judiciário, tido durante muito tempo, como um ramo do Poder Executivo, alcançou, então, uma certa independência, a qual se tornou uma sólida garantia para todos aquêles que houvessem sido espezinhados nas suas franquias individuais. A justiça, nos tempos antigos, era exercida pelos reis; assim, São Luis (Luis IX) distribuia julgamentos, debaixo de uma árvore nó Parque de Vincennes; CarLos I presidiu o processo de JoÃo V - Duque de Bretanha; Carlos VI, o de Carlos II - Rei de Navarra; Francisco I, ao de Marquês de Saluces; Luis XIII, ao do Duque de la Valette. O magistrado, ponderava LA BRUYÈRE, alivia o príncipe da tarefa de julgar os puros; e LoISEAu, lembrava que «les jugés étaient si bien les auxiliaires du prince, que c'était une branche du crime de lèse majesté d'attenter à leur personne, et on les traitait consequemment à leur qualité de mandataires, en leur expédiant de nouvelles commissions, à chaque mutation de prince».

A judicatura, para ser fiel à sua grande missão de restauradora dos direitos conculcados - «nihil honestum esse potest, quod justitia vacat» (nada pode ser honesto quando a justiça falta) (CícEro De Officiis), precisa de gozar de ampla independência, sendo acatadas pelos demais podêres tôdas as suas deliberações, depois de esgotados os recursos processuais. Uma nação, na qual a magitratura não seja cercada de máxima autonomia para proferir as suas sentenças, não poderá alcançar a tranqüilidade pública, porquanto ficará exposta aos rigores do politiquismo, que lhes suplificará as atitudes. Se não admito o arbitrio judicial, porque não tolero a ditadura do sofisma, assaz prejudicial ao sossêgo social como o das baionetas, enfileiro-me, contudo, entre os que querem vê-la dignificada pela obediência aos seus arestos.

O legislador, ao elaborar uma lei, não pode deixar de verificar se os seus artigos se conciliam com os dispositivos constitucionais, e, se, por exigências partidárias, ou pelas injunções do aulicismo, teima em escurecer os princípios basilares da lei magna, é claro que o poder judiciário terá de apreciá-la, fulminando-lhe a inconstitucionalidade manifesta e deixando, portanto, de aplicá-la. A resolução judiciária não representa um capricho individual; não tem de alicerçar-se nos cristalinos textos legais e poderá ser.modificada, ou mantida pela instância superior, por isso que o critério individual, para obter o «pro veritate habetur» deverá ser analisado, minuciosamente, dentro da jurisprudência e da doutrina apadrinhada por bons autores. A regra 
juridica, que lhe incumbe executar, não é obra sua, correndo lhe o encargs árduo de aplicá-la, como foi publicada no órgão oficial; então êle não é o responsável pela falta da técnica da lei, já que não colaborou na sua preparação, em se tornando um mero executor da vontade das câmaras legislativas, muitas vêzes imprevidentes no desempenho das suas importantes funções.

Mas, sendo o respeito à lei um dos indeclináveis deveres dos cidadãos, é evidente que o sentenciador não poderá ser menoscabado pela interpretação dada no caso que lhe foi entregue, pois, se se houver enganado, a correção se dará, na superior instância, que, constituida por juízes mais experientes, firmará a melhor exegese a ser observada.

$\mathrm{Na}$ modernidade, o pedido de revisão da sentença é encaminhado a uma côrte mais graduada, o que não ocorria em tempos antigos, nos quais o próprio prolator da sentença era compelido a justificar as suas resoluções com armas nas mãos - «parce qu'on voyait en lui, non l'organe de la loi, mais l'homme du Seigneur; au lieu qu'aujourd'hui en même temps que les voies légales ne sont ouvertes que contre le jugement, il n'y a de responsabilité pour le juge qu'au cas de débit, ou dans un des cas de dol determinés par le code de procedure» (C. G. Hello - Du Régime Constitutionel).

A diminuição do poder judiciário acarreta terriveis conseqüências sociais, porque, desprotegidos de uma autoridade, que imponha imediata reparação aos atentados às garantias constitucionais, os individuos solucionariam as suas desavenças pessoais com a fraude e a violência, em se multiplicando os homicidios, as lesões patrimoniais, enfim o arbitrio.

Indébita e profundamente perniciosa à segurança individual é, por positivo, a intervenção do poder executivo nas finalidades precipuas da magistratura, já que os intuitos do legislador, ao fazer as leis, ficariam inteiramente frustrados; e convém evocar a conduta de um juiz, tanto que JAIME I tentou intervir na apreciação de uma demanda, que estava sendo instruida na sua presença em lhe negando a menor participação na apuração das provas.

E êsse principio, como nota Pimenta Bueno, foi consignado no estatuto $6 .^{\circ}$ do seu reinado - «soit semblablement déclaré, qui ni sa majesté, ni son conceil privé, n'ont jurisdiction pouvoir, autorité d'examiner ou mettre en question. determiner, ou disposer des biens des sujets de ce royaume. É o principio de que o govêrno não deve de modo algum influir sôbre o regime dos direitos $e$ interêsses particulares confiados à ordem judiciária».

E o próprio Luis XV, acostumando a ver satisfeitos os seus desejos. porque prosseguia na mesma trilha do seu predecessor, ouviu considerações do Chanceler D'Aix que deveriam tê-lo desgostado; ei-las - «Senhor, tanto que o vosso ministro baseia as suas ponderações na razão e na lei, elas se tornam dignas de crédito; quando as suas palavras não se apoiam na lei, bem que se socorra do nome de Vossa Majestade, invocando a vossa vontade, êle se apequena, torna-se suspeito, por isso que vossa vontade não basta para se traduzir numa norma legal a ser cumprida».

Nem sempre as leis se acortam no Direito Natural - e não é inoportuno invocar a lição de ARISTóteles - - «Assim quando se quer que a lei impere, é desejar que sòmente Deus e a razão prevaleçam; mas, em se atribuindo ao homem a supremacia, equivale a deferi-la ao mesmo tempo ao homem e ao animal»; nem sempre as leis se inspiram no Direito Natural e 
provocam perturbações públicas; portanto, o aplicador da lei, com a serenidade, que deve apanagiá-lo, mas que se não confunde com pusilanimidade, deverá cumprir uma lei colisiva ao bem comum?

Evidentemente não, porquanto, sentinela impávida do Direito «Naturale vinculum non dissolvit. Juranaturalia prevalere» (PAPINIANo - Dig. XII, tit. 6, I, 59) - lícito lhe não é acumpliciar - se com os despautérios do poder legislativo, impondo ao povo uma integral obediência àquelas leis.

Poderia ser cumprida a lei, promulgada pelo senado romano, que concedia a Júlio CÉSAR o direito de se apropriar da pessoa e dos bens das damas romanas? E igualmente, essas leis, que retratam a fisionomia totalitária de certos governos, merecem acatamento completo dos que sabem dignificar a garnacha? Se «lex injusta non est lex», uma vez que ela se torna obrigatória para os moradores de uma cidade, porque o seu escopo único é o de lhes oferecer vantagens, é claro que não colimando tais fins, não merecerá a execução dos togados.

Se a lei, como conceituava Santo IsIDORo DE SevilHa, «é prescrita não para a utilidade particular, mas para a utilidade comum dos cidadãos», segue-se que não poderão alcançar execução tôdas aquelas que se destinarem a atender às conveniências, causando, por conseqüência, danos à coletividade, que deve lograr amparo dos dirigentes. O exemplo do Conquistador das Gallias, publicando, durante a sua ditadura, - senaatus-consulto, - de interêsses próprios, vem sendo imitado pelos que alcandoram na alta administração e emprestam ao vocábulo «liberdade» uma significação utilitária; e, após a sua morte, MARCo AnTôni apressou-se em revalidar todos os atos do ditador, em se aproveitando do arquivo do vencedor de Pompeu, como uma arma politica. Ora, as leis humanas, também chamadas positivas, precisam de uniformidade, ou seja, têm de ser aplicadas em todo o território nacional, a fim de que seja evitada a babelização das leis, não sendo recomendável a sua constante alteração; e, ao se alongarem dos preceitos do Direito Natural, as suas disposições não satisfarão os justos anseios populares.

Sei que a obrigação de fazer observada a lei é uma obrigação indeclinável ao juiz; entretanto, percebendo-lhe a flagrante inconstitucionalidade, outro rumo não poderá ser adotado senão o de lhe negar a aplicação, dada a sua função de velar pela pureza da carta constitucional.

Também qualquer ato administrativo, que não estiver abordoado nas leis ordinárias, ou na constituição, deverá ser anulado, pois êle é um defensor dos direitos do homem, cabendo-lhe requisitar a necessária fôrça militar para a garantia plena de tôdas as suas providências com as quais serão imediatamente atendidas as justas reclamações.

Não deverá atemorizar-se o julgador, quando o considerarem um rebelado por haver deixado de apoiar um ato administrativo, ou de acatar uma lei, ou um regulamento de feição anticonstitucional; não e não, engrandece o seu ofício, porque se não acarneirou aos podêres conservando imaculadas as suas vestes judicantes e impondo-se ao aprêço dos seus cidadãos e aos aplausos da consciência. Também permitido não é ao distribuidor da justiça abster-se de julgar qualquer feito, sob o pretexto de que não seriam respeitadas as suas decisões; não e não, pois, ad instar do soldado, a quem não é reconhecida a faculdade de recusar comissão alguma, por se achar convencido de 
que morrerá, devendo desempenhá-la, consoante as ordens emanadas das autoridades superiores, o sentenciador terá de examinar «sine via ac studic» a legitimidade da medida solicitada e concedê-la, com mão intrépida, em curto prazo.

Antes a toga dilacerada pela prepotência dos desrespeitadores da lei suprema, do que amarfanhada pelo comodismo, que embota o caráter e desprestigia as poltronas de qualquer tribunal, envolvendo num desprêzo justificado os seus ocupantes.

A nação brasileira, em 1893, ficou alarmada com a proeza do Almirante Eduardo Wandenkolk, no Estado do Rio Grande do Sul; e, aqui, chegando prêso, foi submetido a conselho de investigação, constituido pelos Almirantes Francisco Pereira Pinto - Barão de Invinheima - João Mendes Salgado - Barão de Corumbá - Dom Carlos Balthazar da Silveira - Conselheiro.

$\mathrm{E}$, num instante em que imperavam delações e pululavam as injustiças, aquêles conceituados marinheiros consideraram-se incompetentes, pois, além de tratar-se de um crime político, o seu autor, conquanto reformado, era senador, e, sòmente com a licença dos seus pares, poderia ser processado, como se lê no parecer elaborado pelo meu saudoso Pai.

Enfrentaram, sem quaisquer temores, o vice-presidente do pais, em exercício, até então acostumado a ser atendido nos seus diferentes caprichos, em se compenetrando das suas inocultáveis responsabilidades de apreciadores do comportamento do seu colega, e à horaciana, desempenhando-as.

«Afinal encontrou o Marechal FLoRIANo alguns cidadãos maduros na experiência da vida, encanecidos no serviço da Pátria, eminentes na carreira das armas, com a precisa coragem para cumprirem com firmeza o seu dever, opondo à barreira da verdade juridica as incursões cada vez mais audazes da fôrça no terreno das garantias individuais, que o congresso desertou, para curar exclusivamente da sua reeleição o mais interêsse da Pátria, sem dúvida (Rui BARBOSA - in Jornal do Brasil de 31 de julho de 1893). Não se ignora que, nas vésperas do julgamento da ordem de habeas-corpus, pleiteada, em prol do Almirante Eduardo Wandenkolk, pelo exímio Rui Barbosa, o Presidente do Pretório Excelso cometeu a imperdoável leviandade de dizer ao dirigente da nação que a maioria dos seus companheiros estava inclinada a deferir a justa pretensão.

E o que ouviu êle? - «Os sénhores dão o habeas-corpus ao Almirante Wandenkolk». E, depois de uma pequena pausa, disse-lhes: e quem lhes dara a ordem de habeas-corpus?

O Ministro Joaquim Toledo Piza e Almeida não se arreceou; e foi o único que, aceitando a convincente argumentação do conspicuo patrono, não hesitou em votar pela concessão do remédio jurídico, perfeitamente cabivel na espécie em aprêço.

Deu, por conseguinte, uma imparagonável lição de peregrina formosura moral; e, quando em 1898. JoAQuim DA CoSTA BARRADAs - exatamente o maior opositor de Rui BARBOSA naquele famoso pleito - ia bater-se por igual medida em favor de deputados e senadores, desterrados por PRUDENTE DE MORAIS, deveria experimentar aquêle sadio contentamento do que, ensurdecendo-se às ameaças, soube comportar-se com a altivez ajustável ao decôro do honroso cargo de intérprete sereno dos textos constitucionais. 
O decreto de 30 de novembro de 1889 , que formulou as regras e tratamentos judiciais, extinguiu os títulos de «Senhor» e «Majestade», usados nos tribunais, porque o poder judiciário devia invocar tão só a sua própria autoridade, sem dependência de poder estranho», e o de 20 de fevereiro de 1890 estabeleceu que os cargos de presidentes do Supremo Tribunal e das Relações fôssem preenchidos por eleição - determinação que vigorou até o advento do regime de 10 de novembro de 1937 . Sempre entendi que a côrte judiciária, principalmente nos paises em que lhe é cometida a altíssima missão de defensora da Constituição, deve conduzir-se com a máxima impavidez, para que sejam totalmente cumpridos e com a maior presteza os seus julgados, a fim deque não sejam parificados ao dardo do velho Priamo - «telum imbelle sine ictu» - como se depara na Eneida (livro II - 544), pois, em se acorcundando. aos paredros, fica completamente desvisilizada.

O Barão do Rio Apa - chefe do estado-maior do exército, ousou censurar - Colendo Tribunal ao comunicar-lhe que haviam sido soltos os militares. amparados por uma ordem de habeas-corpus, nos seguintes têrmos:

«Ela é exorbitante, pois não é justo que aos revoltosos se reconheçam direitos superiores ao poder; o privilégio de aprisionar e de não ser aprisionado. de reter sem nota e formação de culpa por tempo indeterminado, aos defensores: da República e do seu govêrno e de gozar imunidade para não serem presos: antes de culpa formada, apesar de estarem em permanente e continua conspiração» .

Macedo JOAquim (ANTÔNIO JOAQUim) profligou o gesto da dita autoridade militar, dizendo que «sentia arderem-lhe as faces de vergonha e indignação», propondo que fôsse devolvido o ofício desrespeitoso; mas a asperez. dos têrmos em que a redigira não obteve a aprovação unânime dos seus dignos colegas, sendo inserto na data dos trabalhos um protesto da autoria do Ministro Olegário Herculano de Aquino e Castro, ficando ilesa a respeitabilidade daquẹle tribunal. Aliás, conduta meritória teve o Dr. JoÃo EvangelisTA DE Negreiros Sayão Lobato - Visconde de Sabará - quando na Presidência do Supremo Tribunal de Justiça, recebeu do Ministro da Justiça - Conselheiro Francisco de Assis Rosa e Silva - o aviso n $^{\circ} 83$ de 17 de dezembro de 1888 no qual solicitava dos tribunais e juizes a obediência às disposições da Ordem do Livro 3. Tit. $66 \$ 7^{\circ}$ e dos arts. 232 e 237 do Reg. 737 de 1850 , que aconselhavam a fundamentação das sentenças.

«Depois do mais refletido e escrupuloso exame, considero-me no indeclinável dever de pedir a reconsideração de V. Exa. sôbre o incluso aviso, que não pode ter aplicação ao Supremo Tribunal de Justiça, o qual, no desempenho das atribuições que lhe confere a Constituição do Império, não está subordinado ao Poder Executivo, não tendo superior que legalmente possa reprovar ou censurar os atos praticados no exercício de sua privativa e suprema jurisdição.

$\mathrm{Na}$ resposta ao ofício acima mencionado, disse o aludido Ministro da Justiça que «não tem o Govêrno Imperial o intuito de aplicar censura ao Supremo Tribunal de Justiça, ou a qualquer outro tribunal ou juiz, como pareceu a V. Exa. no seu ofício de 25 do corrente mês de janeiro, nem tampouca o de intervir no exercício das respectivas jurisdições, sem dúvida subordinado às determinações da lei, de que nenhuma autoridade isenta, devendo antes a 
sua supremacia mas abrigá-la como exemplo e modêlo dos inferiores; mas sim o de chamar a atenção de todos os juizes e tribunais para as salutares e garantidoras disposições da Ord. Liv. 3. $0^{\circ}$ - Tit. 66, § $7 .^{\circ}$ e dos arts. 232 e 237 do Reg. $n^{\circ} 737$ de 25 de novembro de 1850 , que cumpre sejam observadas, não só no interêsse das partes e direitos em litígio, como também para uniformidade e progresso da jurisprudência.»

Não se conservou silenciosa a egrégia côrte com a resposta, que lhe foi endereçada; e, por sugestão do Ministro Joño JosÉ DE AndRade PINTo, foi lavrado um protesto «por ser atentatório da soberania e independência $d n$ mesmo poder, não reconhecendo superioridade no executivo, de igual categoria politica e com separada esfera de atribuições, para receberem dêste outro poder os juizes e tribunais judiciários censuras e ordens sôbre o modo por que devem êles exercer as funções de sua exclusiva competência, e, com a única inferioridade de hierarquia judicial.»

Quando o Marechal Hermes DA FonsecA, mal orientado, não cumpriu a ordem de habeas-corpus, outorgada aos intendentes municipais desta heróica cidade de São Sebastião do Rio de Janeiro, ouviram-se no recinto do conspicuo tribunal, os veementes votos de Pedro Lessa e Amaro Cavalcanti, cujas conclusões foram endossadas por Manuel Murtinho, Ribeiro de Almeida, Camito Saraiva, Manuel José Espinola, em se mantendo mudos os demais magistrados.

Também Guimarães Natal, verificando que não fôra cumprida a ordem de habeas-corpus, alcançada pelo Dr. Raul FERnANDES para se empossar no govêrno do Estado do Rio de Janeiro. em face de haver sido decretada a intervenção naquela unidade federativa e nomeado um interventor, apresentou um protesto pelo desacato sofrido, que teve o apoio de Alfredo Pinto, Pedro Milieli, Leoni Ramos, Hermenegildo De Barros, para os quais não tinha sido executada a medida solicitada.

Declarou PEDRO dos SANTOS que não cumpria ao Tribunal «votar moções mais ou menos férvidas, ou veementes, em absoluto impróprias de uma corporação judiciária, mas entendia que o acórdão não fôra cumprido».

Ora, se ao Poder Judiciário, em cuja composição devem esmerar-se os Chefes do Poder Executivo, para que todos os cidadãos o considerem sempre o refúgio inexpugnável das suas liberdades, necessário é que seja amplamente prestigiado pelos outros órgãos da soberania nacional, sendo observadas, à risca tôdas as suas soluções de feição pública ou privada, isto é, atinjam os individuos em suas demandas, ou condenem ou absolvam as entidades administrativas, para as quais não devem subsistir privilégios. «O presidencialismo. . . não tendo, como não tem, os freios e contrapesos do regime parlamentar, iria dar na mais tremenda arma do absolutismo tumultuário e irresponsável das maiorias legislativas, das multidões anônimas, e das máquinas eleitorais, se os direitos supremos dos indivíduos e da sociedade, subtraidos pela Constituição, ao alcance de agitações efêmeras, não tivessem, na Justiça, o asilo de um santuário impenetrável».

E haverá quem, conhecendo o que ocorre no sistema presidencial, quz jamais teve o meu apoiamento - desvalioso, não o ignoro - parlamentarista intransigente como sou - dissinta dos conceitos acima referidos, da autoria 
do indeslembrável RuI BARBOSA, o evangelizador intimorato e infatigável da democracia nos rincões, abençoados pelos inesquecíveis jesuitas?

Contou-me o meu saudoso Pai que, visitando, em 1890, a Suprema Côrte, acompanhado por TRACY - Ministro da Marinha - e BlaIne - Chanceler, ouviu dêste as seguintes palavras, guardando-as na sua magnífica memória: «A Suprema Côrte é a chave da nossa abóbada politica», e na verdade, por lhe ser obrigatória a proclamação da constitucionalidade ou inconstitucionalidade das leis, dos regulamentos dos atos praticados pelo Poder Executivo, as suas atividades são de inocultável importância cívica e para as quais se fixam os olhos da opinião pública - «rainha inamolgável» - consoante a opinião do mavioso bardo dos Timbiras».

Se, «o Direito, escreve Rippert, não reclama senão uma coisa: a obediência às leis, é claro que a ação construtiva da judicatura, na execução das leis e regulamentos, em lhes apontando os deslizes, constitui uma exortação ao Poder Legislativo, para que sejam prudentes na feitura das leis, repelindo as inovações prejudiciais à ordem pública e emendando as existentes para o bemestar da coletividade, não se esquecendo da crítica justa de TACITus no tocante aos prejuizos da multiplicidade das leis romanas: - a cortuptissima republica plurimae leges» por enfraquecerem, de continuo, as instituições. Acostumei-me, desde os bancos acadêmicos, a envolver os julgadores numa grande reverência, por considerá-los encarregados de uma função nobilitante e asseguradora das nossas liberdades; e, quando divirjo dos seus despachos e julgados, não me sirvo de expressões impolidas, ou ultrajante à sua dignidade funcional, que não convém apequenar.

O juiz é o intermediário entre a norma e a vida; é o instrumento vivo, que transforma a regulamentação tipica imposta pelo legislador na regulamentação das relações dos particulares; que traduz a norma abstrata da lei, na regra concreta entre as partes, formulada na sentença. $O$ juiz é a viva «ox-jutis»... A sua função especifica consiste na aplicação do Direito. Abraçando o juizo de FRANCESCo FERRARA, porquanto o papel do sentenciador é, seguramente, o de evitar o predomínio de qualquer injustiça, impondo aos seus jurisdicionados a obediência às leis, quero que se convençam êles que, sòmente, devem sujeitar-se à lei magna nacional e às leis ordinárias, para que - effeto sia del ciel nostra gitustizia - como cantou o imperecivel florentino (Paradiso XVIII - 115). 